\title{
28 Research Suare \\ Experiences of the mothers who have tried to intervene with their children's obesity: A qualitative study
}

Meihua Piao ( $\sim$ parkmihua@snu.ac.kr)

Seoul National University Hospital https://orcid.org/0000-0002-2436-6870

Jeongeun Kim

Seoul National University College of Nursing

Ahjung Byun

Seoul National University College of Nursing

Woo Joung Joung

Kyungpook National University College of Nursing

\section{Research}

Keywords: Childhood obesity, Parenting, Health behavior, Qualitative research

Posted Date: February 27th, 2020

DOI: https://doi.org/10.21203/rs.2.24733/v1

License: (c) (i) This work is licensed under a Creative Commons Attribution 4.0 International License.

Read Full License 


\section{Abstract}

Background: Childhood obesity has become increasingly prevalent not only worldwide but also in South Korea. It is known that the lifestyle habits and parents' education were found to be effective. The aim of this research is to explore the experiences of obese children and their mothers regarding obesity and identifying barriers and facilitators to optimize their weight control practices.

Methods: A qualitative method of focus group interview was used for the data collection. Overweight or obese children aged between 12 and 14 and their mothers participated in the interview.

Results: Five pairs of participants (a mother and a child) were interviewed. Mothers tended to be aware of their children's weight issue and tried to manage it themselves by supporting them more actively. They made considerable efforts to change their children's lifestyles with regard to diet and exercise. Additionally, children expected to let their mothers guide them in order to control body weight. However, barriers to achieving their desired body weight were associated with their social contexts that prevented them from continuing their healthy lifestyles. Social context was influential for addressing childhood obesity. The busy and competitive environments in which they live forced the children into busy lifestyles that hindered them from performing their healthy habit promptly.

Conclusions: The results suggest that interventions should be focused on setting a realistic goal and engaging in simple behaviors that could be performed in daily routine. Moreover, ensuring access to a communication channel with other parents or healthcare providers is important.

\section{Introduction}

Childhood obesity has become increasingly prevalent worldwide appearing to affect 155 million people in 2014, with a global increase of $47 \%$ between 1980 and 2014 [1]. In South Korea, the obesity rate has continuously increased from $14.3 \%$ in 2010 to $16.5 \%$ in 2016 [2].

It is known that personal, family and social determinants could influence the childhood obesity. In South Korea, only $14.7 \%$ children engaged in moderate to vigorous daily physical activity in 2015 [3]. The lack of physical exercise could not only be interpreted as simply the individual tendency, but also the social context. The average studying time for elementary school students in South Korea was 5 hours and 23 minutes, which was one hour longer than that of college students [4]. Also, mothers' attention and cooperation toward treatment and their eating habits favorably influence children's weight loss $[5,6,7]$. It is found th at the parents' BMI of obese children is significantly higher than that of normal children which could be inferred that the child's health habits are associated with the family members.

Childhood obesity is likely to lead to adult obesity and chronic disease [8]. It is also associated with psychological problems such as low self-esteem, low self-efficiency, depression, anxiety, negative body image, and poor social status [9]. As the consequences of the childhood obesity, many interventions had been attempted. 
In a meta-analysis of the effects of obesity management programs for children from 2001 to 2011, in South Korea, the complex interventions of exercise, lifestyle habits and parent education were found to be the most effective [10]. Several studies indicated that mothers' attention and cooperation toward treatment, and mothers' eating habits favorably influence children's weight loss $[5,6,7]$. Encouragement was defined as a linguistic or nonverbal message of motivational content provided by parents to facilitate children's physical activity. Parental encouragement was found to be a factor that positively affects participation in physical activity regardless of gender or socioeconomic status [10].

In the social context of South Korea where mothers play a major role in raising children, few qualitative studies have attempted to understand the experience of weight control from the point of view of both obese children and their mothers. Also, behavioral lifestyle interventions taking mothers into consideration which was focused on the context of South Korea were scarce.

In order to design behavioral lifestyle intervention in the future, understanding the perception of obese children and their mothers, and the barriers that contribute to the persistence of habits is required.

The aim of this qualitative research was to explore the experiences of obese children and their mothers regarding obesity and identifying barriers and facilitators to optimize their weight control practices.

\section{Methods}

\subsection{Participants, Recruitment, Ethics, and Contents}

This study is a qualitative research that inductively explores the weight control experiences of mothers who have overweight or obese children aged between 12 and 14 . The reason to choose specific age group to work with was based on the report that prevalence of obesity peaks in fourth grade of elementary schools and decreases in fifth and sixth grades [12].

The method of focus group interview was used for the data collection. One of the distinct features of this method was its group dynamics, hence the type and range of data generated through the social interaction of the group were often deeper and richer than those obtained from one-to-one interviews [10]. The optimum size for a focus group was six to eight participants (excluding researchers), but focus groups can work successfully with as few as three and as many as 14 participants [13].

In this study, five pairs of participants (a mother and a child) were selected and the inclusion criteria were as follows: (1) Elementary school students from the fourth to sixth grades whose age-specific BMI index is over the 85th percentile according to the Korean Pediatric Society Standard, (2) Capable of communicating and responding to the interview, and (3) Understanding the purpose of the study and signing the research agreement.

\subsection{Data collection}


Data collection was performed between March and May 2015. Two researchers who participated in a course on qualitative research conducted the interviews. All data coders/analysts were trained in qualitative research.

In the selection of participants, elementary school nurses were contacted first given the difficulty of recruitment of elementary school students. With the support of the school nurses, the contact information of the participants was collected. We contacted the mothers and recruited the final voluntary participants who met the inclusion criteria.

We conducted separate interviews with the mothers and children. On the first day, we interviewed the group of mothers and on the second day, we interviewed the group of children. The average duration of the interview was two hours.

This paper focused on the experience of weight control process, with particular emphasis on daily life practices and barriers for weight control. The main questions were summarized as follows: (1) What are the considerable aspects of your child being obese (addressed to the mothers)? (2) What are the considerable aspects of you being obese (addressed to the children)? (3) What are the most difficult aspects of child's weight management (addressed to the mothers)? (4) What are your eating habits (addressed to the children and mothers), and (5) How to motivate children to perform the weight control action (addressed to the mothers)?

All interviews were recorded with the consent of the participants, and the recordings were transcribed and documented as soon as the interviews were conducted. In cases where the transcribed data was not comprehensible or interpretable, another follow-up interview was conducted to enhance the reliability of data and analysis.

\subsection{Data analysis}

The qualitative content analysis method used was as follows. First, we tried to form an overall opinion by reading the interview contents repeatedly. Second, we carefully read each paragraph, and formulated meanings from these statements. Third, we labeled the codes and categorized them according to the subjects' experience. Lastly, codes were categorized according to their relationship and connectivity, and the arranged codes were organized according to their hierarchy of importance.

\subsection{Validity and reliability}

This study complied with the credibility, fitness, auditability, and confirmability standards provided by Sandelowski to ensure quality [14].First, the participants were interviewed using open-ended questions, which allowed them to share their experiences frankly and expressively in their own language. All interviews were recorded in the language of the participants. We ensured whether there were contradictory contents in the process of data by asking the participants to check if our interpretation was correct. 


\section{Results}

\section{Participants}

In total, five children and five mothers were interviewed. Table I shows the characteristics of the participants. The age range of the children was 12-13 years and one was female. Four of them were classified as obesity and one was classified as overweight based on the WHO criteria. In South Korea mothers play an important role in raising children, so we only included mothers in this study. Two of them had college/university education, and three had full time job, one had part time and one was not employed.

\section{Themes}

Five themes such as ambivalence about food restrictions, active intervention for weight loss, facing obstacles in weight management, fear of obesity stigma and changing obesity coping strategy were summarized and described in the Table 2.

\section{Theme 1. Ambivalence about food restrictions}

Participants felt strong ambivalence about their 'food policy' which puts strict restrictions on amount, time, and contents of children's food intake.

They were struggling with their efforts to reduce obesity due to the anxiety that they might retrogress against healthy growth and development and the 'want to feed' mind that they naturally feel as parents.

\section{1) Conflicts between weight management and growth}

In order to manage obesity, the diet needs to be controlled, but food intake is recommended for development during the growth period. Mothers experienced inner conflicts about whether to feed their children in a food-restricting situation while feeling anxious about weight control efforts that may interfere with height growth. They also hoped that fat would manifest as height, and manifested beliefs about obesity that it could be solved by height growth.

Wanting to eat, children always say, "I am hungry" a lot when they have done a lot of activities. I provide them with yogurt or low fat food as alternatives, but honestly, I feel really bad. I am also worried that they would not get taller at this rate.

\section{2) The sorrow of "happy to see my child eat"}

The mindset of wanting to feed their children well is common for parents. The interviewed mothers felt sad when they had to limit their children's food intake.

As for being a parent, I feel the most happiness when my child eats well, honestly. As old Korean farmers would feel happy and relieved when it would rain during drought, I fell the happiest when I see my child 
eats well. But people who have been really fat can understand how heartbroken parents feel when they restrict their children from eating. Strictly saying "No more food", when child really wants to eat and asks some more is really painful.

\section{Theme 2. Active intervention for weight loss}

The interviewed mothers made aggressive attempts to lose their children's weight. They actively intervened to manage their children's obesity with diet control, made efforts to increase physical activity, and participated in hospital obesity programs.

\section{1) Struggling to quit negative eating habits}

They attempted to change their child's negative eating habits such as excessive eating in a short time, intake of too much meat or high-fat food, late night eating into healthier habits like low fat, vegetable rich diet. In addition, they aggressively tried to control their child's weight by limiting the speed of time and amount of food intake.

For a year, in an attempt to control my child's weight, I checked his weight in the morning and evening, gave him smaller portions of rice, limited food intake after a certain time in the evening, and restricted having chicken and pizza at night. I did all of this.

My family divided the ham equally among four members. If ham is served on one plate, the speed of the child's food intake becomes faster in an attempt to have yet another slice of ham due to food cravings. If ham is given separately, the child eats slower.

\section{2) Trying hard to increase physical activity}

The interviewed mothers were working hard to control their child's weight gain. Many of them let their child enroll various kinds of sports program to increase physical activity, and some of them searched for and have their child attend hospital treatment program for weight loss.

I did several things. For about two years, we visited several oriental medical clinics and participated in diet programs in a university hospital. I really spent a lot of money. Oriental medicine programs, taking oriental medicines, getting acupuncture... we tried many things. While participating in these interventions, my child lost weight, but I cannot continue doing these steadily unless I am very rich.

Because my child is a girl, she did not really exercise much. So I made her take taekwondo lessons on purpose. This way, she would at least do jump ropes at the lessons. She continued taking taekwondo lessons for a while, but it did not help her lose weight.

\section{Theme 3. Facing obstacles in weight management}

The interviewed mothers faced various situations which were not favorable to their child's weight control efforts: social event which goes with food all the time, busy life routine with no time for exercise, and the 
absence of safe space for kids to play.

\section{1) Social life constraints and a permissive atmosphere for food}

Social gatherings and celebrations, which are mostly with food, are challenging for the child's weight control. Exposed to various kinds of food, especially so called junk or fast food, which stimulate many children's appetite, mothers get a lot of stress choosing between getting along with others and letting the child enjoy junk food and giving up socialization to continue their weight control effort. What makes matters worse is kid's snack culture. While the rest of the children enjoy high calorie food like pizza and hamburger, it is difficult for mothers not to allow their child to enjoy the meal. Mothers realize that controlling their own appetite and weight is not easy, but controlling their child's is a lot more difficult and even painful.

Children cannot continue their social lives if they have meals three times a day only at home. Under this condition, if they visit their friends house or their friends come over to our place, my children cannot eat even though all their friends eat. Thus, mothers who control their children's diet are also stressed. Mothers want to control diet for their children, but in reality, it is almost impossible. Kids anyway eat pizza and drink coke no matter what in their social lives, but restricting only my children from those... from a parent's perspective....

In contrast to the negative perception of obesity, the permissive and recommended culture for food intake also upsets participants' commitment to control their child's weight gaining. As there is no clearly visual cut between chubby and obese, mothers sometimes lose their strong will to control their child's weight. Constant conflict with their child about what to eat or how much they can eat also alleviate mother's resolution to be strict on diet, letting their child eat as much as they want, thinking once would be ok. However, when they are accused or criticized of being too strict on food intake and weight control within social relations, the mixed and confused feelings about their child's weight control are transformed into anger for not making themselves understood with regard to their agony of restricting foods from their children who crave to eat.

In the past, my child asked me a question while picking up food with the fork, "Can I eat this, mom?" and tried to get my approval in social gatherings. Then, others would say, "Hey, why are you raising your kids that way? It is breaking your child's spirits." Hearing these, I felt really mad! Very frustrated! Nobody gets how I feel.

\section{2) Limited time and narrow space}

Children and their mothers have a strict life routine. Whether they are working or stay-home mothers, their daily lives are so busy that they cannot concentrate only on their children's weight management. Elementary school students themselves rarely find time for weight control during their busy lives. Even in the competitive learning atmosphere of elementary schools, there is not enough time for adequate outdoor activities and physical activities. 
First, kids are so busy! My kid is in the third grade and comes home at 6:30. He has to play at least one sport to avoid getting fat or spend time working with art or a hobby he likes. He also has to do his schoolwork. So after school, he goes to a private academy for taekwondo and one art class and comes home at 6:30. After giving my kids a bath and taking care of my second child, I try to make conversation but it is already time to sleep by then. We are so short on time. I have very little time to spend with my child.

The interviews with children revealed that there is a strong lack of leisure time for physical activity after regular school hours. Children go to school and take private academic lessons after school.

I don't have time to work out or play outside. After getting up in the morning, I go to school and take little rest after school at home. I then attend private English and math classes for two hours. After those, it is 7:30 when I get home. I have dinner and do my homework from school and private lessons. Then, I go to bed at 10 (from the interview with kids).

The interviewed mothers who have children who go to elementary school recognized that the lack of safe space for their children to play freely was also a negative barrier to their children's obesity management. They thought that safe spaces for physical activities such as riding bicycles and in-line skates should be provided but that it is not possible to use public facilities such as school playground or permitted sports centers. They argued that there is not enough space for safe physical activity. Furthermore, participants were concerned about the increased time spent indoors due to smartphone use, computer games, television, and Internet use along with a significant decline in physical activity. Four among the five interviewed children had their own smartphones.

People used to play in front of their houses in the old days, but now there is very little safe space for kids to play due to many cars. Swimming pools. Gymnasiums. They are always occupied with some type of event. So there is only school playground left for children to play, but sometimes, they are not allowed to use the school playground. There is really no space for kids to hang out and play.

After school, I take a bus and go for private lessons. I then go home and take rest. At home, I usually play games with my cellphone. But mom found out about it and I am no longer allowed to play games.

\section{3) Limitations of mothers' intervention}

The interviewed mothers experienced some limitations while intervening in their children's weight control. Mostly, they felt that they were already separated enough from their fourth- to sixth- grade children to be able to empathize completely. Obese person's strong will to reduce weight might be the most important factor for controlling weight, but there are limitations with respect to the things mother can help for their child, and the degree that the child might tolerate to control his or her appetite. The interviewed mothers realizing they got very sensitive about what and how much their child eat during meal time expressed their concerns that their effort to control their child's weight might be exacerbating their relationship with their child. The interviewed mothers, concerned about the control of their children's diet, found that 
mothers were sensitive in the dining room, a space for conversation. They expressed their concern about the deteriorating relationships with their children.

Even though girls get teased and stressed out, they do not open up to their parents. Even though they are worried and concerned, they do not feel close enough to their parents to express their situations to their parents. So I tried to attend counseling with my kid and found out that there were a lot of incidents I did not know about. Also, a mom cannot stick to her kid physically 24/7.

Recently, we talked a lot about controlling the amount of rice eating. For twice or three times a week, which did not happen before, I recently started to say to my kid "Will you eat two bowls of rice?" or "Are you already finished?" without realizing.

Mothers alone did not control their children' weights. Dietary habits and preferences of other family members also needed to be considered, and their responses to weight management were also affecting participants' efforts to control their children's weight.

The atmosphere of the house is not helping children lose weight and only mothers try to make their children lose weight. The children never change then. It can cause reverse effects. Only the relationship between a mother and a child could fall apart.

Fathers say, "Everything is okay," "Two bowls of rice are okay," and "Should we have some late night snack?" My husband does not get fat despite eating a lot; therefore, he can say, "Eat whatever you want and have some late night snack." Then, the child eventually eats something along with the rest of the family.

On the other hand, as the child's obesity increases and the exercise becomes more necessary, the child enters a state of dilemma in which he feels burdened by physical activities and refuses to exercise. It is not participants losing weight, but their child's weight that they have to help lose. Regardless of how hard mothers try, they cannot substitute their efforts to lose weight and they cannot always be with their children and encourage them.

When she started to get fat, she stopped playing. She feels tired even after moving a little bit. Earlier, she moved around all the time, but from the point when she started to get obese, she says that she feels pain in her ankles. She cannot even do a lot of exercise. She gets exhausted very easily. She has to keep on exercising with similar intensity steadily and in order to do so, mom has to stay by her side all the time. But I can't do that because I work. She complains about pains in her ankles and knees after jump ropes and avoids doing things that make her tired.

\section{Theme 4. Fear of obesity stigma}

The interviewed mothers were afraid that their children's obesity would be publicly acknowledged, and this resulted in general distrust and dissatisfaction with the school health curriculum and lack of sensitivity on the part of the teachers. 


\section{1) Weight loss effort that can't be disclosed publicly}

The interviewed mothers were strongly aware of the negative effects of children's obesity on their children in their peer group. They sensitively perceived the psychological pressure, alienation, and inferiority that their children experienced in their peer group for being obese or overweight and recognized that appearance was a common criteria of hierarchy among children and adolescents. Knowing that it is quite different to be obese and to be publicly known as being obese, participants were more concerned about stigmatization and emotional pain due to obesity for their child than the physical state of being obese. Their child might be the target of bullying among schoolmates if he or she got officially turned out to be obese, therefore participants did not want the weight control effort to be publically known

We don't have time to go to counseling, but I am a bit afraid of it too. Also, there are some people who do not consider it a good idea. Because the child would then be labeled 'obese.' I don't want to accept that my child is obese but it's the truth. But because of being obese, my kid gets hurt and I know about it.

Kids, these days, have this thought that because they are obese, they will be teased in front of their friends and they are concerned about this. Kids are more likely to be hurt than adults. Adults usually acknowledge their current status and become responsible about it, but kids really get hurt. In my kid's case, he/she got so hurt that I am really concerned...

\section{2) Discontent with the school health system}

The interviewed mothers shared common mistrust and dissatisfaction with the school's obesity management system and teachers' lack of sensitivity. Mothers who were highly anxious about their children being labeled as "obese" and were teased about it expressed strong concern that obesity measurement and notices publicly conducted would undermine the self-esteem of obese children and cause alienation and bullying among peer groups. Participants were also highly distrustful about the lack of sensitivity among teachers and lack of attention to disclosure of personal information. They expressed that they had no intention and reason to make their children participate in obesity management and measurements conducted at school in a situation where children are stigmatized as "obese kid" at one measurement and not cared for afterwards.

There is body composition analyzer but it is not well utilized. In order to use Inbody, children have to visit the school nurse, and then it is revealed to other kids in class. A school nurse does measure individual students privately and the measurement is conducted when children visit the nurse. So, it becomes public in class. After the results come out, homeroom teachers do not secretly give them to the child. Instead, they say "your results came out" and everyone in class gets to know about those. Kids are very sensitive about weight.

Our school brings obese students together and measure them. Therefore, every student becomes aware of it and nobody wants to participate. I myself know about this situation and do not let my child 
participate. Because he/she would be teased. As I mentioned before, children in need of this and help are hiding.

On the other hand, some participants complained about the national obesity project. They criticized the lack of facilities for children to use to manage their obesity problem.

I have found out that there are ongoing obesity projects nationwide, and there are other related on-going projects, but my actual experiewas that, when I really try to participate, there is literally nothing I can do. There are many exercising facilities run by public health centers. I don't know if you have visited there, but they are mainly operated for adults. There is nothing for children.

\section{Theme 5. Changing obesity coping strategy}

The interviewed mothers compared the advantages and disadvantages of all the measures with which they tried to solve their children's obesity problem. They modified their coping strategies for obesity, such as promoting their children's favorite activities and becoming flexible in diet control among their active interventions.

\section{1) Weighing the pros and cons of weight loss attempts}

The interviewed mothers measured the psychological stress that they experienced with their children and the actual dietary adjustment effect after attempting to solve obesity in various ways. The weight loss was not worth the psychological stress related to diet control and restriction. The stress that children experience and the psychological stress, pressure, sadness, anger, and frustration that mothers suffer in the process of controlling the diet for the children, as well as the conflicts in the mother-child relationship are so huge that mothers were threatened by the signs of worsening relationships with their children.

I have been trying to control, restrict, and make my child exercise for about a year. But he was under extreme stress. Eventually, he was suffering something similar to depression. It was too much!! He lost about 2 kilograms and gained 20 kilograms of stress! I felt that way. Compared to the results of weight management, the child goes through too much stress!

My child weighs twice more than other kids, so I tried really hard to make him lose weight. But suddenly, I thought to myself, "This is not working." Getting obese slowly, it felt like I gave my child a hard time just to make him gain only one kilogram instead of three. Since the age of seven, he has been gaining about $3 \sim 4 \mathrm{~kg}$ every year. I thought about making him gain one kilogram by trying really hard or three kilograms from letting him be free from all that weight control. Before even reaching the optimal weight, it seemed like my child would suffer to death from all the restrictions. So after trying for a year, I just let him eat whatever he wants.

The interviewed mothers were also aware of the severity of the psychological trauma experienced by obese children. Obesity problems should not only focus on weight loss, but also on the need to provide 
psychological treatment to address the negative effects experienced by obese children caused by peers' teasing, negative self-image, atrophy, depression, and low self-esteem.

Children who really need weight control are mentally exhausted. In reality, diet control is not really important to these kids. It is better to treat their mentally ill minds and then talk about food control. It never works when you say "lose weight," "exercise," and "control your diet" to very depressed kids with low self-esteem who always hide around. Therefore, basic treatments should precede first.

\section{2) Taking a step back to passive intervention from an active one}

The interviewed mothers who struggled for their children's weight loss and escaping obesity realized that the actual weight loss effect was insignificant compared to the stress they both had experienced. Therefore, instead of factitious and deliberate interventions, they took passive measures such as encouraging their children to perform their favorite physical activities and reducing the chances of food exposure that does not help their children's weight loss. The interviewed mothers eventually changed obesity coping strategies toward physical activity and eating habits that could be enjoyed and practiced steadily in daily lives rather than focusing on weight loss and sensitivity to physical activity and food.

My child and I tried really hard and lost only 1 2 kilograms. Instead of stressing him out about weight control to achieve a certain body image, I allowed him to eat just the right amount and ensured that he avoided excessive eating late at night.

I discussed with my child, and she said that she enjoys dancing more than exercising, so she dances 3 to 4 hours once a week at her dance lesson. I used to send her to Kendo lesson during weekdays, but the amount of activity done during Kendo was not as much as I expected. She stopped doing Kendo due to the increased possibility of injuries. Overall, I think that without mothers' free time and children's diligence which makes them do something steadily, things get difficult.

\section{Discussion}

The aim of the present study was to explore the obese children and their mothers' experiences regarding weight control and to identify barriers and facilitators to optimize their practices. This study's findings suggest that mothers tend to be aware of their children's weight issue and tried to manage it themselves by supporting them more actively. They made considerable efforts to change their children's lifestyles with regard to diet and exercise. Additionally, children expected to let their mothers guide them in order to control body weight. However, barriers to achieving their desired body weight were associated with their social contexts that prevented them from continuing their healthy lifestyles.

Mothers in this study have expressed conflicts related to food restrictions. They were emotionally satisfied on seeing their children eat well. Additionally, they were worried that food restriction could interfere with their children's physical growth. On the other hand, they condemned themselves that such attitude could make them withdraw from the program as a consequence. As previous study had shown, 
the participants' depictions of obesity revealed a disconnection between knowledge and perception [15]. It is noted that, although parents were aware of the health risks associated with obesity in adulthood, they did not talk about their children's body weights with potential problems in the present tense [16]. It can be speculated that providing information related to children's fat distribution and body size changes with age is necessary when designing the healthy lifestyle habit program, for increasing motivation and leading to greater long-term success.

Mothers expected their children to be more physically active and exhibit healthy eating habits. They tended to manage the obesity issue not only by themselves, but also by using a clinical program. However, they faced family conflicts with their husbands and grandparents. Usually, in South Korea, grandparents continue to have a significant influence as a family member. Families where not all members agree on how to implement the healthier lifestyle faced challenges [17]. In previous research on obese adolescents, the intention to reduce weight was interfered with quarrels between parents [18]. This study found that mothers faced resistance from their husbands regarding the compliance as time consuming; they also faced a generation gap with respect to their grandparents in terms of the perception of food restriction. It was recognized that family behavior was essential for the development of weight control and weight loss activity [19]. As shown in this study, the inconsistent family members' reactions could confuse children about their intention to reduce weight. When designing the program, providing guidance about the eating and exercising habit and conflict management methods would be necessary. Moreover, making a mutual agreement with the family members before enrolling in the program is important to minimize the resistance.

Many factors influenced childhood overweight and obesity management; however, the social context and social factors were the most influential. The average studying time for elementary school students in South Korea was 5 hours and 23 minutes, which was one hour longer than that of college students. While Korean students' learning ability index was ranked second in the world after Finland, the Child-Youth Happiness Index was the last among the OECD countries [4]. The competitive learning environment compelled them to follow extracurricular lessons. The children who participated in the interview did say that there was not enough time for them to perform physical activities. The children we interviewed return home from school or private lessons at around 8 p.m. and the time for dinner is past 9 p.m. Moreover, they also mentioned that they prefer delivery food which is more convenient although it is considered unhealthy. As the consequence, the social environment experienced by the interviewed children was considered as the most important barrier to maintain lifestyle behavior changes in the long term.

In their social context, the interviewed mothers expressed social stigma in relation to obesity. They were worried that their children may experience bullying at school if enrolled in the weight control program and if their classmates came to know about it. Earlier research has concluded that bullying was significantly associated with low self-esteem in overweight children [20,21]. Therefore, the interviewed mothers suggested that the intervention should be designed in a supportive manner that could protect the children's self-esteem. Additionally, providing the communication context by sharing tips with other peer group to discuss barriers in the environment was important. As other studies have suggested, primary 
care setting consultation should be provided to mothers to address their fear of being blamed for their child's weight problem and concern about their child's mental well-being should be provided.

This study's findings suggest that setting realistic goals was important to support the participants throughout the program. Regarding the social context in South Korea, it is not easy to make children have dinner before $7 \mathrm{pm}$ or join the sports center after class. The intervention should be focused on simple behavior that could be performed in daily routine and gradually carry out the target behavior repeatedly in the same situation, and also make the simple behavior automatic and habitual.

Moreover, it is necessary to provide a communication channel with health professionals or other parents who have the same problem to discuss barriers for emotional support.

This study had some limitations. We planned to interview the children and the mothers separately. However, some of the mothers brought their other children along because there was no one to take care of them. This may have influenced their attention during the interview. Another limitation was the small sample size. It was not easy to recruit obese children, given the social stigma and blame attached to parents of children with obesity.

\section{Conclusion}

The results of this study demonstrate that the social context was influential for addressing childhood obesity. Mothers and children had a positive attitude regarding the weight control, but the busy and competitive environments in which they live forced the children into busy lifestyles that hindered them from performing their healthy habits promptly.

The results suggest that interventions should be focused on setting a realistic goal and engaging in simple behaviors that can be performed in daily routine. Moreover, ensuring access to a communication channel with other parents or healthcare providers is important.

\section{Declarations}

\section{Ethics approval and consent to participate}

This study was approved by the Institutional Review Board of Seoul National University in South Korea (IRB No. 1510/002-010).

All participants were informed of the study purpose and procedures, particularly that the interviews would be recorded and that the collected data would not be used for any purposes other than research. The participants were also informed that they had the right to decline or withdraw from participation before or during the study. Informed consent was obtained from each participant before data collection and all the information gathered was de-identified, to ensure confidentiality.

\section{Consent for publication}

Page 14/18 
Not applicable

\section{Availability of data and materials}

The data that support the findings of this study are available from the corresponding author upon reasonable request

\section{Competing interests}

The authors declare that they have no competing interests.

\section{Funding}

This research was supported by Basic Science Research Program through the National Research Foundation of Korea (NRF) funded by the Ministry of Education (810-20150020).

\section{Authors' contributions}

Meihua Piao planned the conception and research design.

Meihua Piao and Ahjung Byun interviewed the participants to acquire data.

Joung Woo Joung did the data analysis and interpretation.

Jeongeun Kim, Meihua Piao, Joung Woo Joung and Ahjung Byun drafted the article and revised it critically for important intellectual content. All authors reviewed and contributed to the preparation of the final manuscript.

\section{Acknowledgements}

We would like to thank all the participants of the interviews in this study. We also want to show our gratitude to Yunmi Jo in particular for her contribution of connecting the participants.

\section{References}

1. Ng M, Fleming T, Robinson M, Thomson B, Graetz N, Margono C, Mullany EC, Biryukov S, Abbafati C, Abera SF, Abraham JP, Abu-Rmeileh NME, Achoki T, AlBuhairan FS, Alemu ZA, Alfonso R, Ali MK, Ali R, Guzman NA, Ammar W, Anwari P, Banerjee A, Barquera S, Basu S, Bennett DA, Bhutta Z, Blore J, Cabral N, Nonato IC, Chang J-C, et al. Global, regional, and national prevalence of overweight and obesity in children and adults during 1980- 2013: a systematic analysis for the Global Burden of Disease Study 2013. Lancet. 2014;384:766-81.

2. Ministry of Education: School Health Survey (2016).

3. Ministry of Health and Welfare: The 1st child policy basic plan South Korea (2015).

4. http://news.sbs.co.kr/news/endPage.do?news_id=N1004064413\&plink=ORI\&cooper. 2017 
5. Golan M, Crow S. Parents Are Key Players in the Prevention and Treatment of Weight-related Problems. Nutrition Reviews. 2004. doi: 10.1111/j.1753-4887.2004.tb00005.x

6. Janicke DM, Steele RG, Gayes LA, Lim CS, Clifford LM, Schneider EM, Carmody JK, Westen S. Systematic Review and Meta-Analysis of Comprehensive Behavioral Family Lifestyle Interventions Addressing Pediatric Obesity. Journal of Pediatric Psychology. 2014; doi: 10.1093/jpepsy/jsu023

7. Wadden, T. A., Stunkard, A. J., Rich, L., Rubin, C. J., Sweidel, G., \& McKinney, S. (1990). Obesity in black adolescent girls: a controlled clinical trial of treatment by diet, behavior modification, and parental support. Pediatrics, 85(3), 345-352.

8. Lakshman R, Elks CE, Ong KK. Childhood obesity. Circulation. 2012;126:1770-9.

9. Sahoo K, Sahoo B, Choudhur AK, Sofi NY, Kumar R, Bhadoria AS. Childhood obesity: causes and consequences. J Family Med Prim Care. 2015;4:187-92.

10. Lee, M. H., \& Baek, S. S. (2012). A meta-analysis of optimal exercise time and frequence for fat loss in overweight elementary school students. The Korean Journal of Elementary Physical Education, 18(2), 199-210.

11. Trost SG, Sallis JF, Pate RR, Freedson PS, Taylor WC, Dowda M. Evaluating a model of parental influence on youth physical activity. American journal of preventive medicine. 2003;25:277-82.

12. Lee G, Ham OK. Factors Affecting Underweight and Obesity Among Elementary School Children in Soulth Korea. Asian Nursing Research. 2015;9:298-304.

13. Gill P, Stewart K, Treasure E, Chadwick B. Methods of Data Collection in Qualitative Research: Interviews and Focus Groups. Br Dent J. 2008;204:291-5.

14. Sandelowski M. The problem of rigor in qualitative research. ANS Adv Nurs Sci. 1986;8:27-37.

15. Rich SS, DiMarco NM, Huettig C, Essery EV, Andersson E, Sanborn CF. Perceptions of health status and play activities in parents of overweight Hispanic toddlers and preschoolers. Fam Community Health. 2005;28:130-141.

16. Eli K, Howell K, Fisher PA, Nowicka P. "A little on the heavy side": a qualitative analysis of parents' and grandparents' perceptions of preschoolers' body weights. BMJ Open. 2014; doi: 10.1136/bmjopen2014-006609

17. Hampl S, Demeule M, Eneli I, Frank M, Hawkins MJ, Kirk S, Morris P, Sallinen BJ, Santos M, Ward WL, Rhodes E. Parent perspectives on attrition from tertiary care pediatric weight management programs. Clin Pediatr. 2013;52:513-9.

18. Lindelof A, Nielsen CV, Pedersen BD. Obesity treatment-more than food and exercise: a qualitative study exploring obese adolescents' and their parents' views on the former's obesity. International Journal of Qualitative Studies on Health and Well-being. 2010; doi: 10.3402/qhw.v5i2.5073.

19. Gruber, K. J., \& Haldeman, L. A. (2009). Peer reviewed: Using the family to combat childhood and adult obesity. Preventing chronic disease, 6(3).

20. Danielsen YS, Stormark KM, Nrdhus IH, Mæhle M, Sand L, Ekornås B, Pallesen S. Factors Associated with Low Self-Esteem in Children with Overweight. Obesity Facts. 2012;5:722-33. 
21. White, A., O'Brien, B., Houlihan, T., Darker, C., \& O'Shea, B. (2012). Childhood obesity: parents fail to recognise, general practitioners fail to act.

\section{Tables}

Table 1. Descriptive statistics of the sample

\begin{tabular}{|cccclll|}
\hline Age & Gender & Height & Weight & BMI & Education & Working status \\
\hline 12 & M & 123 & 43 & 28.42 (obesity) & High school & Not employed \\
\hline 12 & M & 132 & 41 & 23.53 (overweight) & High school & Part time \\
12 & M & 139 & 57 & 29.5 (obesity) & College/ university & Full time \\
13 & M & 144 & 58 & 27.97 (obesity) & College/ university & Full time \\
\hline 13 & F & 141 & 44 & 27.16 (obesity) & High school & Full time \\
\hline
\end{tabular}

Table 2. Mothers' experiences of managing children's obesity

\begin{tabular}{|c|c|}
\hline Themes & Sub themes \\
\hline Theme 1. & Conflicts between weight management and growth \\
\hline Ambivalence about food restrictions & Happy but also worried to see my child eat \\
\hline Theme 2. & Struggling to quit negative eating habits \\
\hline Active intervention for weight loss & Trying hard to increase physical activity \\
\hline Theme 3. & Social life constraints and a permissive atmosphere for food \\
\hline \multirow[t]{2}{*}{ Facing obstacles in weight management } & Limited time and narrow space \\
\hline & Limitation of mother's intervention \\
\hline Theme 4. & Weight loss effort that should be made covertly \\
\hline Fear of obesity stigma & Discontent with the school health system \\
\hline Theme 5. & Weighing the benefit and loss of weight control \\
\hline Changing obesity coping strategy & Taking one step back from aggressive to passive intervention \\
\hline
\end{tabular}


Page 18/18 